\title{
Controle via agência em plataformas algorítmicas ${ }^{1}$
}

\author{
Julio Cesar Lemes de Castro \\ https://orcid.org/0000-0002-8961-2104 \\ I - UNISO \\ Sorocaba (SP), Brasil
}

Resumo: Este artigo de articulação teórica, baseado em pesquisa bibliográfica, aborda a relação entre controle e agência em plataformas algorítmicas. O controle envolve a coleta e a análise de dados a partir das atividades e interações dos usuários, com o desígnio de discernir padrões e tendências, o que permite antecipar e direcionar comportamentos, correspondendo assim a um aparato de vigilância intensiva e permanente. Ao mesmo tempo, cada usuário possui certo nível de agência, podendo, ao alterar seu curso de ação, influenciar a maneira como ele é apreendido e, portanto, interpelado pela plataforma. Dessa combinação de fatores, emerge um modelo paradigmático de governança algorítmica, consistindo em um modo de controle flexível, modulado de acordo com a agência do usuário, que se expressa na variabilidade de seu input - em outras palavras, um controle via agência.

Palavras-chave: controle; agência; vigilância; governança algorítmica; plataformas algorítmicas.

Abstract: Control through agency on algorithmic platforms. This article of theoretical articulation, based on bibliographic research, focuses on the relation between control and agency on algorithmic platforms. Control involves the collection and analysis of data on user activities and interactions, aimed at discerning patterns and trends, which enables behaviors to be anticipated and guided, thus corresponding to an intensive and permanent surveillance apparatus. At the same time, each user has a certain level of agency, and by altering his course of action, can influence the way he is apprehended and therefore interpellated by the platform. From this combination of factors emerges a paradigmatic model of algorithmic governance, consisting of a flexible form of control, modulated according to the user's agency, which is expressed in the variability of his input - in other words, a control through agency.

Keywords: control; agency; surveillance; algorithmic governance; algorithmic platforms.

1 Uma versão inicial deste artigo foi apresentada no XLII Congresso Brasileiro de Ciências da Comunicação (Intercom), realizado em Belém (PA) de 2 a 7 de setembro de 2019. 


\section{Introdução}

Este artigo insere-se numa linha de pesquisa que tenho explorado nos últimos anos, em torno do tema da governança algorítmica (CASTRO, 2018). Trata-se de uma investigação sobre o funcionamento dos algoritmos como tecnologia de poder nos diversos setores da vida social e, especialmente, no que denomino plataformas algorítmicas (CASTRO, 2019).

Em tais plataformas, o usuário geralmente se cadastra e passa a ser gerido conforme os dados que ele fornece ou que são extraídos de sua atividade. Isso engloba os recursos do Google, tomados conjuntamente (mecanismo de busca, Google Maps, Gmail, YouTube etc.); redes sociais, como o Facebook, o Twitter e o Instagram; sites de comércio eletrônico, como a Amazon; provedores de transmissão contínua (streaming), como a Netflix e o Spotify; serviços de economia do compartilhamento, como a Uber e o Airbnb; e dispositivos acoplados à internet das coisas, como as tecnologias vestíveis.

O foco específico aqui é a articulação entre controle e agência em plataformas algorítmicas. São examinadas, inicialmente, as formas pelas quais os usuários são controlados nas plataformas. Em seguida, consideram-se as maneiras pelas quais nelas se manifesta a agência dos usuários, bem como os entraves a esta. Levando em conta esses fatores, almeja-se delinear a natureza peculiar da governança presente nas plataformas.

Trata-se de um texto de reflexão teórica, estribado em pesquisa bibliográfica, que inclui referências a estudos empíricos e casos particulares. Em virtude do caráter abrangente da abordagem adotada, não são cotejadas as especificidades de cada plataforma. Obviamente, há oscilações entre os tipos de controle e agência nas diversas plataformas, mas a preocupação cardeal é elucidar o que eles têm em comum.

\section{Plataformas como instâncias de controle}

A rigor, o controle nas plataformas não é exercido diretamente sobre os usuários, mas sobre seus traços, recombinados em relações, as quais adquirem maior relevância do que os indivíduos propriamente ditos. Por isso, a extração de dados desempenha nelas papel crucial. Para chamar a atenção para o fato de que esses dados são em geral capturados, e não supridos intencionalmente pelos usuários, uma proposta é qualificá-los de capta, em lugar de data (DRUCKER, 2011). Na mesma toada, a expressão "colonialismo de dados" (COULDRY; MEJIAS, 2019) denota uma operação de expropriação semelhante àquela que distingue o colonialismo tout court.

As plataformas preocupam-se, ademais, com a vetorialidade das relações entre os traços obtidos de seus usuários, procurando identificar padrões nelas presentes e prever desdobramentos. A partir daí, buscam agenciar comportamentos, tendo em vista nomeadamente finalidades de consumo, posto que seu modelo de negócios se assenta na venda de publicidade ou na comercialização direta de produtos e serviços. Para tanto, 
são construídos perfis ad hoc com base em recortes de dados. Perfis afins derivados de diferentes usuários, por seu turno, são agrupados num cluster, que corresponde ao escopo de determinado anúncio ou oferta.

Além de imprimir uma certa orientação às atividades e interações em seu interior, as plataformas estabelecem normas de funcionamento, que intentam conciliar seu modelo de negócios com o interesse dos usuários e com regulações vigentes na sociedade. Essa normatividade costuma ser implementada rigidamente pelas corporações que são proprietárias das plataformas. Os próprios algoritmos encarregam-se de parcela substancial dessa tarefa, bloqueando, por exemplo, o impulsionamento artificial de links no mecanismo de busca do Google ou a publicação de imagens contendo nudez ou violência na linha do tempo do Facebook. Mas é preciso recorrer também a pessoas contratadas para a moderação de conteúdo, um ofício mentalmente insalubre, do qual se incumbem amiúde firmas terceirizadas radicadas em países menos desenvolvidos, como mostra o documentário The cleaners (Im Schatten der Netzwelt, direção de Hans Block e Moritz Riesewieck, 2018).

Diferindo do panóptico descrito por Foucault (1975), no qual múltiplos corpos se posicionam ao redor de um sensor central, que os monitora um a um, o sistema de controle nas plataformas é equiparável a um "panespectro" (DELANDA, 1991), no qual múltiplos sensores incidem concomitantemente sobre todos os corpos. Em contraste com o prisioneiro do panóptico, que não sabe quando está sendo observado, mas sabe de que maneira pode ser observado, o usuário da plataforma localiza-se num criptóptico, no qual ele sabe que está sempre sendo vigiado, mas não tem consciência de todas as formas como isso se dá (VAIDHYANATHAN, 2011). Como o controle não está mais ancorado na visualidade, como no panóptico, pode-se chamá-lo de pananalítico (KOOPMAN, 2015). Por conta igualmente da prevalência nele da captação e da análise de dados, é válido caracterizá-lo como "vigilância de dados" - do vocábulo inglês dataveillance, proposto por Clarke (1988) e já dicionarizado. Nessa mudança de paradigma, a vigilância torna-se intensiva e permanente: uma profusão de dados é coletada ininterruptamente, mesmo que sua utilidade não seja imediata, mas definida a posteriori, atentando às relações encontradas.

Nos anos 1950, discutindo as estratégias possíveis no jogo de par ou ímpar, Lacan pondera que, ainda que não premeditemos uma dada sequência de lances, acabamos seguindo padrões ditados por nosso inconsciente. E especula sobre o potencial preditivo de um computador capaz de discernir tais padrões: "Não é impensável que uma moderna máquina de calcular, isolando a frase que, sem que ele o saiba e a longo prazo, modula as escolhas de um sujeito, venha a ganhar além de qualquer proporção costumeira no jogo de par ou ímpar" (LACAN, 1966, p. 59). As plataformas algorítmicas atuais, captando e esmiuçando uma enorme quantidade de dados sobre o usuário, habilitam-se a detectar padrões desse jaez e antecipar comportamentos. Nesse aspecto, representam o que Thrift (2005) designa como "inconsciente tecnológico", a ação de uma tecnologia poderosa que impacta a vida de cada um à sua revelia. 
Há circunstâncias em que a plataforma está mais informada sobre pormenores do usuário do que ele próprio, ou consegue perceber mudanças em sua vida antes dele. Num lance anedótico, uma mulher descobre que estava grávida devido a uma aparente anomalia em sua Fitbit (McNEAL, 2016), uma espécie de tecnologia vestível - mais precisamente, uma pulseira que registra dados corporais, agregados a uma plataforma com dados dos outros usuários, os quais podem comunicar-se em fóruns específicos. De modo mais geral, um estudo sobre relacionamentos românticos, apoiado na extensa base de dados do Facebook (BACKSTROM; KLEINBERG, 2014), propõe-se a estimar, a partir de sua duração e da análise das redes dos envolvidos, a probabilidade de um rompimento com sessenta dias de antecedência.

O controle exercido pela plataforma pode recair deliberadamente sobre as emoções. Num experimento polêmico, realizado pelo Facebook sem aviso aos usuários afetados (KRAMER et al., 2014), verifica-se que pessoas expostas a menor número de conteúdos positivos em seu feed de notícias acabam gerando menos postagens positivas e mais postagens negativas, ao passo que aquelas confrontadas com menor número de conteúdos negativos apresentam comportamento inverso. Na Austrália, um documento interno produzido por executivos do Facebook garante a anunciantes ser viável identificar, monitorando postagens e fotos, quando um adolescente se sente "inseguro", "sem valor" e "precisa de uma injeção de confiança" (LEVIN, 2017), algo que constitui inegavelmente uma mina de ouro para a publicidade.

Esse comprometimento direto das plataformas em práticas controversas de vigilância não é atípico. Em 2010, é revelado que os veículos do Google StreetView coletavam dados de redes de wi-fi abertas, incluindo, consoante a Federal Communications Commission (FCC) norte-americana, "nomes, endereços, números de telefone, URLs, senhas, e-mails, mensagens de texto, registros médicos, arquivos de vídeo e áudio, e outras informações de usuários de internet" (KRAVETS, 2012). Isso sem contar as inúmeras ocorrências de problemas de privacidade ou segurança, em várias partes do mundo, envolvendo as imagens - de propriedades e, inevitavelmente, no decurso do processo, de pessoas - captadas pelo serviço. Considerando essas e outras vicissitudes, é sintomático que o lema não oficial "Não seja mau" (Don't be evil), impregnado por muito tempo na cultura corporativa do Google, tenha sido discretamente removido do código de conduta distribuído a seus funcionários (CONGER, 2018).

Adicionalmente, as vulnerabilidades das plataformas são exploradas por terceiros. Após a Cambridge Analytica ter cumprido papel importante tanto no referendo sobre o Brexit, no Reino Unido, como na eleição de Donald Trump, nos Estados Unidos, em 2016, descobre-se que ela violara regras do Facebook, as quais, por sua vez, eram fiscalizadas precariamente. Como apontam investigações por ocasião da celeuma, a empresa comprara de um pesquisador dados de usuários que se tinham submetido a um teste psicológico por ele elaborado, mais os dados dos amigos desses usuários (CADWALLADR; GRAHAM- 
HARRISON, 2018). Instado a clarificar o incidente, o Facebook assume que o vazamento alcança 87 milhões de pessoas (KANG; FRENKEL, 2018).

Toda essa obsessão por vigilância é facilmente compreensível: visto que a interpelação de cada usuário se alicerça nos dados disponíveis, ela granjeia eficiência com o incremento do montante e da variedade desses dados. A tendência, consequentemente, é que o controle se torne ubíquo, desdobrando-se em múltiplas frentes e mesclando dados de todas elas. Numa plataforma como a do Google, que abrange uma gama de recursos, não é difícil coordenar as informações oriundas de todos. Mas ela não se cinge a isso, procurando ampliar ainda mais seu repertório com a aquisição de bases de terceiros, incluindo um vasto cadastro de transações via cartões de crédito nos Estados Unidos. Na medida em que o modelo de negócios das plataformas se esteia na vigilância, assistimos ao surgimento de um autêntico "capitalismo de vigilância" (ZUBOFF, 2019).

Isso tem também repercussões políticas. É fato conhecido que a internet se origina de pesquisas conduzidas sob os auspícios do Departamento de Defesa norte-americano durante a Guerra Fria, e sua colonização pelas corporações de tecnologia a partir dos anos 1990 não impede que se mantenham vínculos com o aparelho estatal. Agências oficiais de inteligência têm a prerrogativa de cruzar não só as informações de órgãos governamentais, mas igualmente aquelas requisitadas junto às corporações sobre cada cidadão. Nesse contexto, é natural conjecturar que, "se o Grande Irmão voltasse no século XXI, ele retornaria como uma parceria público-privada" (ASH, 2013). Nos Estados Unidos, essa tendência acentua-se em resposta aos atentados terroristas de 11 de Setembro. "Enquanto você lê isso online", comenta Edward Snowden (2015) no The New York Times, "o governo dos Estados Unidos toma nota." Mas o programa de vigilância mais ambicioso nesse quesito parece ser o que tem sido desenvolvido na China: um sistema de crédito social integrando bancos de dados governamentais e corporativos numa plataforma comum. Em razão dessa aproximação, as fronteiras entre o universo do consumo e o universo policial-repressivo se diluem, cada pessoa se convertendo em uma espécie de "duplo consumidor-criminoso" (PASSAVANT, 2005). A ideia mesma de privacidade vem a ser associada à de ilicitude, como na frase de Eric Schmidt, então CEO do Google, em entrevista à jornalista Maria Bartiromo, da CNBC: "Se você tem algo que não quer que ninguém saiba, talvez não devesse estar fazendo isso em primeiro lugar" (GOOGLE CEO, 2009).

\section{Agência articulada ao controle}

O controle nas plataformas discrepa do regime disciplinar também porque ele não se dá de um jeito vertical, hierárquico, centralizado, moldando cada usuário de acordo com um padrão. Como na caracterização da sociedade de controle por Deleuze (2003), trata-se de um controle flexível, modulado continuamente em conformidade com seu alvo. Nos termos de Bauman e Lyon (2013), uma "vigilância líquida". Isso se deve sobretudo 
à sua recursividade, entendida na acepção de feedback, o qual, segundo Wiener (1989, p. 33), o criador da cibernética, é "a propriedade de ser capaz de ajustar a conduta futura pelo desempenho passado". Se a concepção de controle é primordial na cibernética, como indica o título de uma das obras principais de Wiener (1961), ela sofistica-se a ponto de falar-se hoje em uma "cibernética de controle" (ROSE, 2004, p. 237).

À diferença dos meios de comunicação de massa, que tendiam a induzir uma atitude mais passiva por parte do espectador, do tipo coach potato, os algoritmos pressupõem sua atividade. Nas plataformas, a interpelação de cada um apoia-se no input que ele próprio provê, direta ou indiretamente. Com isso, o usuário determina em alguma medida como ele é encarado e, por conseguinte, abordado pela plataforma. Se está descontente com a operação do algoritmo, ele pode propor-se a treiná-lo de certa forma, ensinando-lhe seus interesses e adaptando-o a seus gostos. O mecanismo de feedback complementase, assim, com um mecanismo de feedforward. Isso, porém, não nos autoriza a inferir que o usuário tenha autonomia perante a plataforma, no sentido de evadir seu controle. $\mathrm{Na}$ realidade, tal controle torna-se ainda mais efetivo, já que a plataforma passa a ter um retrato mais fiel de cada usuário. Em outras palavras, este colabora voluntariamente para aperfeiçoar o controle ao qual se submete, que tem características de uma "vigilância participativa" (POSTER, 1990)

Temos então uma situação em que a agência, em tese o oposto do controle, se conjuga com ele e the confere maleabilidade, configurando um controle via agência. A conjugação entre ambos esvaece a dualidade entre as orientações para o interior e para o exterior, qualificadas por Riesman (2001) respectivamente de "introdirigida" e "alterdirigida", posto que o controle via agência atua mediante elementos internos que interpelam o usuário a partir de fora. Tal como em certas artes marciais a força do oponente é empregada contra ele, aqui a iniciativa de alguém presta-se a controlá-lo. Isso faz desse controle uma modalidade disfarçada de poder, que Lash (2007) denomina "pós-hegemônico". O correlato do aparente retraimento do poder é a responsabilização maior pelo controle por parte de quem é controlado. Não se trata exatamente da "servidão voluntária", na linha de La Boétie (1922), mas do que poderíamos julgar uma servidão autodirigida, que é ativa e não se reconhece como servidão. Escorando-se na agência do usuário, portanto, o controle logra não apenas adequar-se constantemente a seu alvo, mas camuflar-se enquanto controle.

A própria plataforma, para calibrar sua interpelação do usuário, ocasionalmente se lança ao encalço de seu feedback. No Facebook, questionários periódicos exibem vários tipos de conteúdo lado a lado e solicitam do usuário a manifestação de sua preferência em cada caso. Mas a calibragem, na grande maioria das vezes, é feita automaticamente, pois, ao utilizar a plataforma, alguém seleciona o tempo todo: se um tipo de conteúdo Ihe é oferecido e ele não reage positivamente, o algoritmo muda o apelo; se sua atenção é despertada, conteúdos similares imediatamente Ihe serão mostrados. Isso faz parte 
da experiência ordinária dos usuários, que não tardam a constatar sua lógica e a aderir ao jogo. É verdade que essa lógica pode ser demasiadamente bem-sucedida, quando, a título de exemplo, um internauta consulta um produto num site e começa a deparar-se com anúncios desse produto em outros sites, levando-o (em particular quando ingênuo ou inexperiente) a sentir-se perseguido.

O controle via agência envolve a subordinação da agência ao controle. Como o algoritmo de uma plataforma equivale a uma "caixa preta" (PASQUALE, 2015), que ninguém sabe exatamente como funciona, isso limita a capacidade do usuário de influenciá-lo. As corporações não desvendam os detalhes desse funcionamento, seja para eludir a concorrência, tratando-o como segredo comercial, seja para evitar investidas para burlá-lo, que visem alguma vantagem ou o mero prazer da disrupção. Sobra ao usuário manobrar por tentativa e erro, avaliando a cada passo o resultado de sua ação. Além disso, as alternativas propiciadas dentro das plataformas, condicionadas por sua arquitetura e pelas atividades e interações pretéritas do usuário, são relativamente restritas. Os algoritmos valorizam a escolha, mas trata-se de uma escolha com cartas marcadas, que não contém nenhuma inflexão radical. Isso pode, inclusive, ter implicações mais amplas, que ultrapassam as plataformas: alguém que se habitua a decidir com base em padrões do passado tende a perder a aptidão de imaginar rupturas no futuro, experimentando uma redução da margem de indeterminação em sua vida.

A agência subordina-se ao controle não somente devido aos limites de seu raio de manobra, mas igualmente em função da natureza que ela assume. Atuar nas plataformas requer, mais do que a aceitação formal (concordância com os termos de serviço) e tácita (obediência às regras), a internalização de seu modus operandi. Isto é, estamos diante de um modo de subjetivação, no sentido foucaultiano. As plataformas tomam o usuário como quem não cessa de escolher, fiando-se em um critério de otimização que se declina em cada um conforme padrões específicos, e é definido por essas escolhas. O usuário emerge, dessa maneira, como um verdadeiro Homo algorithmicus, cuja lógica interna reproduz a da plataforma. Se no fetichismo da mercadoria há uma naturalização do valor abstrato desta, a incorporação da lógica algorítmica da plataforma naturaliza as abstrações que afetam o usuário, via métricas e cálculos. Quando me proponho a adestrar o algoritmo a distinguir meus padrões é porque, ao utilizar rotineiramente a plataforma, fui adestrado como um agente otimizador que escolhe seguindo padrões. Acomodar o algoritmo a minhas predileções implica tratá-lo como uma ferramenta a meu serviço, uma terceirização de minha lógica algorítmica interna, mas apenas porque já internalizei sua lógica, de sorte que há de fato uma continuidade entre ambas. E essa internalização é facilitada pelo fato de que algo semelhante vigora em outras instâncias da vida social, à guisa de lógica algorítmica ou da racionalidade econômica hegemônica em nossa época.

Efetivamente, com todas as suas limitações, a iniciativa dos usuários, expressa em seu engajamento nas plataformas, pode ser entendida no âmbito do neoliberalismo. 
O típico sujeito neoliberal é um "empreendedor de si mesmo" (FOUCAULT, 2004), que se dedica a ampliar continuamente seu capital humano. Esse empreendedorismo de si figura nas plataformas frequentemente como investimento em sua própria imagem nas redes sociais (CASTRO, 2016b). Por seu design, as plataformas tendem a favorecer o empenho por rendimento: quando se mensuram sistematicamente as reações a uma postagem, por meio de curtidas, comentários e compartilhamentos, cada qual é estimulado a buscar popularidade por esse caminho. Tais injunções de performance (CASTRO, 2016c) embutidas nos algoritmos são expedientes de controle que se imiscuem na agência.

A contrapartida do empreendedorismo de si é a reificação (CASTRO, 2014). Se em Lukács (1972) a reificação se dá através do mercado, aqui ela consiste na identificação aos algoritmos, mas cumpre notar que estes assomam como sucedâneos do mercado. Ao investir em si, o usuário constrói-se como produto, ainda que tenha consciência limitada disso. E, nesse ponto, ele também espelha a plataforma, cujo modelo de negócios é sustentado pela venda da audiência para os anunciantes. "Você é o produto", declara Tim Cook (2018), CEO da Apple, aludindo aos usuários do Google, embora sem nomeá-lo explicitamente. Idêntico enunciado intitula um artigo do The New York Times, dirigido aos usuários do Facebook (ROSENBERG; DANCE, 2018). Este, inclusive, enxerga a necessidade de contestar expressamente tal proposição: "Se eu não estou pagando pelo Facebook, eu sou o produto? Não. Nosso produto é mídia social" (GOLDMAN, 2018). O tom pejorativo conferido à identificação do usuário a um produto é explicável, pois, além de indicar uma falha de reconhecimento (HONNETH, 2005), a reificação torna explícito o controle, em contraponto à agência associada ao empreendedorismo.

A subordinação da agência ao controle pode ainda ser apreendida sob outro ângulo. Reduzido a Homo algorithmicus, o usuário cai inexoravelmente sob o campo gravitacional da plataforma na qual se insere, tornando-se sua extensão. Trata-se da subsunção de uma unidade algorítmica menor a uma maior, da qual a primeira se torna sinédoque. No confronto entre ambas, a primeira está em desvantagem, em virtude de sua capacidade de processamento inferior. A agência baseada no input do usuário é restrita, porque ninguém conhece e controla tão bem seu próprio input. Se decido treinar o algoritmo para reconhecer meus padrões, com vistas a acelerar tal reconhecimento, só posso fazer isso até certo ponto, uma vez que a longo prazo ele está mais apto a identificar meus padrões do que eu próprio.

Num certo grau, o controle sobre o usuário é terceirizado pela plataforma para seus contatos, que têm alguma ascendência sobre ele - a qual pode ser significativa, no caso de influenciadores. Essa terceirização é possível porque os outros também se conduzem como unidades algorítmicas, sinédoques da plataforma. O episódio Nosedive (direção de Joe Wright, 2016), da série Black Mirror, da Netflix, é exemplar sob esse prisma. Seu mote é uma sociedade na qual todos fazem parte de uma única rede, conferindo notas uns aos outros em função tanto dos conteúdos postados online quanto das interações 
na vida cotidiana, o que gera uma estratificação de reputações. Temos aí uma "vigilância distribuída", para usar a locução de Bruno (2013), ou um omnióptico, onde há "muitos vigiando muitos" (JOYCE, 2003, p. 13-16).

Assim, o investimento do usuário na construção de sua imagem estimula a conectividade, enquanto intensificação das interações nas plataformas. Para Mark Zuckerberg, fundador do Facebook, com a consolidação das redes sociais, "as pessoas realmente passaram a sentir-se confortáveis não apenas em compartilhar mais informações, e de tipos diferentes, mas mais abertamente e com mais pessoas. Essa norma social é simplesmente algo que evoluiu com o tempo" (ZUCKERBERG apud JOHNSON, 2010). Além de ser numa boa medida induzida, tal disposição dos usuários em compartir informações serve de pretexto para justificar o uso de suas informações pela plataforma. Em audiência judicial que discute os vazamentos de dados dos usuários para a Cambridge Analytica, Orin Snyder, advogado de defesa do Facebook, argui:

ao compartilhar com cem amigos em uma plataforma de mídia social, o que é um ato social afirmativo de publicar, divulgar, compartilhar informações ostensivamente privadas com uma centena de pessoas, você [...] negou qualquer expectativa razoável de privacidade (UNITED STATES DISTRICT COURT, NORTHERN DISTRICT OF CALIFORNIA, 2019, p. 7).

Ainda quando as plataformas captam padrões inconscientes ou seus mecanismos são ignorados pelos usuários, estes têm alguma agência nesse processo, pois intuem a existência de um controle e o autorizam tacitamente. A cumplicidade - ou resignação - do usuário com o controle ao qual se sujeita deriva mormente de um cálculo de reciprocidade: ele cede seus dados à plataforma (algo oficializado, via de regra, pelos termos de uso desta) em retribuição às vantagens presuntivamente trazidas por sua utilização, no que tange a acesso a conteúdos, contatos etc. Seus dados convertem-se, destarte, em moeda de troca. Um experimento de laboratório proclamado como o maior até então no campo de economia da privacidade (JENTZSCH et al., 2012) conclui que a maioria dos participantes se dispõe a sacrificar sua privacidade para obter menores preços. Esse tipo de cálculo explica a divergência entre a preocupação com privacidade externada por usuários e sua postura efetiva. Mas, conquanto o cálculo de reciprocidade, que justifica a adesão às plataformas a despeito da preocupação com privacidade, sugira que esteja em jogo aí um simples toma lá, dá cá, mesmo o suposto equilíbrio dessa transação é passível de contestação, na medida em que o usuário de certo modo labuta de graça para a plataforma, que lucra à custa de seus esforços.

As facetas das relações de poder nas plataformas fazem delas ilustrações por excelência da governança algorítmica. A noção de governança tem a conotação de "governar sem governo" (RHODES, 1996), por duas razões perfeitamente aplicáveis às plataformas: por um lado ela vai além da visão contumaz de governo como 
administração do Estado, por outro ela enfatiza um modelo de gestão que incorpora a dimensão horizontal e distribuída das redes. Outrossim, essa noção tem livre curso na esfera das grandes corporações, que controlam as plataformas mais representativas.

Uma referência também útil é a teoria lacaniana dos discursos, que correspondem às modalidades fundamentais de laço social. Lacan concede um estatuto especial ao discurso do capitalismo, que está associado ao capitalismo tardio e pode ser considerado o laço social preponderante em nossa época, operando de modo distinto dos demais. Na formalização algébrica desse discurso, o sujeito ocupa o lugar dominante e aparentemente está em situação de controle, determinando o saber responsável pela produção dos gadgets e objetos de consumo em geral. Num exame mais detido, todavia, ele subordina-se ao gozo extraído destes (CASTRO, 2012; CASTRO, 2017). Similarmente, nas plataformas, a agência dos usuários se eclipsa diante do protagonismo dos algoritmos, que procuram canalizar justamente o gozo dos usuários: o controle não consiste em impor-lhes algo desagradável, mas em seduzi-los por intermédio daquilo que mais os atrai. Com efeito, uma forma eficiente de naturalizar práticas de vigilância, como o reconhecimento facial, é seu uso lúdico (ELLERBROK, 2011).

Um experimento pessoal de uma professora norte-americana, para fins de pesquisa acadêmica, certifica como é árduo escapar ao controle dos algoritmos. Ela resolve testar se seria possível esconder sua gravidez, ao longo de toda a sua duração, das ferramentas de coleta e análise de dados. Para tanto, ela evita qualquer menção a seu estado nas redes sociais de que participa; pede o mesmo a seus familiares e amigos; emprega um navegador que desvia o tráfego através de servidores estrangeiros; e faz compras somente em dinheiro ou com vale-presentes adquiridos com dinheiro. No balanço de sua tentativa (VERTESI, 2014), ela atesta ter sido algo custoso, que trouxe inconvenientes a suas relações e a deixou em posição idêntica à de pessoas que realizam atividades ilícitas. Em suma, nas condições em que vivemos, a crença de que alguém teria a opção de preservar sua privacidade é, em larga medida, ilusória. De resto, em muitas circunstâncias, omitir dados da plataforma torna menos produtivo o uso desta, porquanto a customização da experiência ensejada depende desses dados.

Nesse quadro, o derradeiro reduto da agência dos usuários termina sendo uma insatisfação difusa. Uma sondagem do Pew Research Center (SMITH, 2018) junto ao público norte-americano sinaliza uma atitude de reserva perante os algoritmos e o papel por eles desempenhado em recomendações e na tomada de decisões. Os questionamentos abarcam a violação da privacidade, a propensão à desinformação e ao sensacionalismo, a permissão de conteúdos e comportamentos desagradáveis, a apreensão falha do que é relevante pessoalmente e socialmente, a presença de vieses, a dificuldade de lidar com nuances e complexidades e a injustiça de avaliações. A insatisfação às vezes redunda em afastamento temporário ou definitivo de uma plataforma por parte do usuário, ou até em movimentos coletivos nesse sentido, como o \#DeleteFacebook, que ganha corpo quando 
estoura o escândalo da Cambridge Analytica, em 2018. Numa sociedade altamente conectada, entretanto, esse caminho arrisca-se a acarretar isolamento social.

Se o controle das plataformas sobre cada usuário tomado isoladamente é geralmente eficiente, isso já não vale para grupos organizados que agem em diapasão dentro delas sem obedecer a suas diretrizes, recorrendo a contas falsas, robôs, fake news e discurso de ódio. São máquinas de guerra híbrida (CASTRO, 2020), montadas por correntes políticas e campanhas eleitorais, como ocorreu na eleição à presidência de Trump e, dois anos depois, no Brasil, de Jair Bolsonaro. Aliando os préstimos de voluntários com os de profissionais contratados, devem sua eficácia à associação da horizontalidade das redes com a verticalidade de uma gestão centralizada. Marcadas pela excentricidade vis-à-vis as plataformas, cujo controle elas desafiam como se representassem um comando paralelo, as máquinas de guerra híbrida têm um impacto potencialmente danoso nas plataformas ao prejudicar sua reputação entre usuários, anunciantes e autoridades.

\section{Considerações finais}

Percebemos, no decorrer do texto, a convergência de noções de vários autores, dando conta de diversas facetas do controle nas plataformas algorítmicas, ainda que algumas tenham sido concebidas há duas ou três décadas. Isso acontece porque esse controle tende a refletir as modalidades predominantes de controle social e tecnológico no período recente.

Quando focamos a relação entre controle e agência nas plataformas, fica evidente que ambos estão sempre presentes: não se trata apenas de controle, nem apenas de agência. Por outro lado, não temos aqui uma simples polaridade, uma contraposição entre dois termos equivalentes.

O que se averigua é que um dos polos tem mais força que o outro, de maneira tal que o segundo acaba caindo sob a zona de gravidade do primeiro, sendo subsumido pelo primeiro. Ou seja, nas plataformas, em última instância, o controle prevalece sobre a agência.

Isso não significa, contudo, que a agência dos usuários simplesmente se desvaneça, obscurecida pelo controle. Na prática, vigora uma situação na qual a agência se mantém, mas confinada sob a égide do controle, como uma espécie de bolsão circunscrito pelo controle, que busca incessantemente mobilizá-la, operando como um controle via agência.

O controle das plataformas, embora incidindo sobre a ação dos usuários em seu interior, não impede que eles as utilizem em chave socialmente transformadora, por exemplo como instrumentos de mobilização política (CASTRO, 2016a). De qualquer modo, a consciência desse controle recomenda cautela quanto à magnitude possível desse uso. 
Julio Cesar Lemes de Castro é pós-doutorando na Uniso, com bolsa PNPD/Capes, e membro do Laboratório de Teoria Social, Filosofia e Psicanálise da USP. É doutor em Comunicação e Semiótica na PUC-SP, com pós-doutorados em Psicologia Social na USP e em Comunicação e Cultura na UFRJ.

julio@jclcastro.com.br

\section{Referências}

ASH, T. G. If Big Brother came back, he'd be a public-private partnership. The Guardian, Jun 27, 2013. BACKSTROM, L.; KLEINBERG, J. Romantic partnerships and the dispersion of social ties: a network analysis of relationship status on Facebook. In: ACM Conference on Computer Supported Cooperative Work and Social Computing, 17., 2014, Baltimore. Proceedings... 2014.

BAUMAN, Z.; LYON, D. Liquid surveillance: a conversation. Cambridge (UK) and Malden: Polity Press, 2013.

BRUNO, F. Máquinas de ver, modos de ser: vigilância, tecnologia e subjetividade. Porto Alegre: Sulina, 2013.

CADWALLADR, C.; GRAHAM-HARRISON, E. Revealed: 50 million Facebook profiles harvested for Cambridge Analytica in major data breach. The Guardian, Mar 17, 2018.

CASTRO, J. C. L. Consumo contemporâneo e discurso do capitalismo. Lumina, v. 6, n. 1, p. 1-7, junho de 2012.

O amor virtual como instância de empreendedorismo e de reificação. Galáxia, v. 14, n. 27, p. 72-84, junho de 2014.

Das massas às redes: comunicação e mobilização política. In: JESUS, E.; TRINDADE, E.; JANOTTI, J.; ROXO, M. (Org.). Reinvenção comunicacional da política: modos de habitar e desabitar o século XXI. Salvador: EDUFBA/Brasília: Compós, 2016a. p. 149-166.

Neoliberalismo, autoimunidade e redes sociais. Interin, v. 21, n. 1, p. 145-163, janeiro/ junho de 2016b.

Social networks as dispositives of neoliberal governmentality. Journal of Media Critiques, v. 2, n. 7, p. $85-102,2016 \mathrm{c}$.

Between material and virtual worlds: fetishism and the discourse of capitalism. American Imago, v. 74, n. 1, p. 23-39, Spring 2017.

Redes sociais como modelo de governança algorítmica. Matrizes, v. 12, n. 2, p. 165-191, maio/agosto de 2018.

Plataformas algorítmicas: interpelação, perfilamento e performatividade. Revista Famecos, v. 26, n. 3, p. 1-24, setembro/dezembro de 2019 .

Máquinas de guerra híbrida em plataformas algorítmicas. E-Compós, ahead of print, 2020.

CLARKE, R. A. Information technology and dataveillance. Communications of the ACM, v. 37, n. 5, p. 498-512, May 1988.

CONGER, K. Google removes “Don't be evil” clause from its code of conduct. Gizmodo, May 18, 2018. 
COOK, T. A message from Tim Cook about Apple's commitment to your privacy. Sep 17, 2018. Disponível em: <https://web.archive.org/web/20140918034518/https://www.apple.com/privacy/>. Acesso em: 1 jul. 2019.

COULDRY, N.; MEJIAS, U. A. The costs of connection: how data is colonizing human life and appropriating it for capitalism. Stanford: Stanford University Press, 2019.

DeLANDA, M. War in the age of intelligent machines. New York: Zone Books, 1991.

DELEUZE, G. Pourparlers: 1972-1990. Paris: Minuit, 2003.

DRUCKER, J. Humanities approaches to graphical display. Digital Humanities Quarterly, v. 5, n. 1, 2011.

ELLERBROK, A. Playful biometrics: controversial technology through the lens of play. Sociological Quarterly, v. 52, n. 4, p. 528-547, Fall 2011.

FOUCAULT, M. Surveiller et punir: naissance de la prison. Paris: Gallimard, 1975.

. Naissance de la biopolitique: cours au Collège de France, 1978-1979. Paris: Gallimard/ Seuil, 2004.

GOLDMAN, R. Hard questions: what information do Facebook advertisers know about me? Apr 23, 2018. Disponível em: <https://newsroom.fb.com/news/2018/04/data-and-advertising/>. Acesso em: 1 jul. 2019.

GOOGLE CEO Eric Schmidt on privacy. 2009. 1 vídeo (33 sec). Disponível em: <https://www.youtube. com/watch?v=A6e7wfDHzew $>$. Acesso em: 1 jul. 2019.

HONNETH, A. Verdinglichung. Frankfurt am Main: Suhrkamp, 2005.

JENTZSCH, N.; PREIBUSCH, S.; HARASSER, A. Study on monetising privacy: an economic model for pricing personal information. Athens: European Network and Information Security Agency (ENISA), 2012.

JOHNSON, B. Privacy no longer a social norm, says Facebook founder. The Guardian, Jan 11, 2010.

JOYCE, P. The rule of freedom: liberalism and the modern city. London: Verso, 2003.

KANG, C.; FRENKEL, S. Facebook says Cambridge Analytica harvested data of up to 87 million users. The New York Times, Apr 4, 2018.

KOOPMAN, C. The algorithm and the watchtower. The New Inquiry, Sep 29, 2015.

KRAMER, A. D. I.; GUILLORY, J. E.; HANCOCK, J.T. Experimental evidence of massive-scale emotional Contagion through social networks. PNAS, v. 111, n. 24, p. 8788-8790, Jun 17, 2014.

KRAVETS, D. An intentional mistake: the anatomy of Google's wi-fi sniffing debacle. Wired Magazine, May 2, 2012.

LA BOÉTIE, É. Discours de la servitude volontaire, suivi du Mémoire touchant l'édit de janvier 1562. Paris: Bossard, 1922.

LACAN, J. Écrits. Paris: Seuil, 1966.

LASH, S. Power after hegemony: cultural studies in mutation? Theory, Culture \& Society, v. 24, n. 3, p. 55-78, May 2007.

LEVIN, S. Facebook told advertisers it can identify teens feeling "insecure" and "worthless". The Guardian, May 1, 2017.

LUKÁCS, G. History and class consciousness: studies in Marxist dialectics. Translated by Rodney 
Livingstone. Cambridge (MA): MIT Press, 1972.

MCNEAL, S. A woman realized she was pregnant after she saw weird data on her Fitbit. BuzzFeed News, Feb 8, 2016.

PASQUALE, F. The black box society: the secret algorithms that control money and information. Cambridge (MA) and London: Harvard University Press, 2015.

PASSAVANT, P. A. The strong neo-liberal state: crime, consumption, governance. Theory \& Event, v. 8, n. 3, 2005.

POSTER, M. The mode of information: poststructuralism and social context. Cambridge (UK) and Malden: Polity, 1990.

RHODES, R. A. W. The new governance: governing without government. Political Studies, v. 44, n. 4, p. 652-667, Sep 1996.

RIESMAN, D. The lonely crowd: a study of the changing American character. rev. ed. New Haven and London: Yale University Press, 2001.

ROSE, N. Powers of freedom: reframing political thought. Cambridge (UK), New York, Melbourne, Madrid and Cape Town: Cambridge University Press, 2004.

ROSENBERG, M.; DANCE, G. J. X. "You are the product": targeted by Cambridge Analytica on Facebook. The New York Times, Apr 8, 2018.

SMITH, A. Public attitudes toward computer algorithms. Pew Research Center, Nov 16, 2018.

SNOWDEN, E. J. The world says no to surveillance. The New York Times, Jun 4, 2015.

THRIFT, N. Knowing capitalism. London, Thousand Oaks and New Delhi: SAGE, 2005.

UNITED STATES DISTRICT COURT, NORTHERN DISTRICT OF CALIFORNIA. Facebook, Inc. consumer privacy user profile litigation. May 29, 2019. Disponível em: $<$ https://assets.documentcloud. org/documents/6153329/05-29-2019-Facebook-Inc-Consumer-Privacy.pdf >. Acesso em: 1 jul. 2019.

VAIDHYANATHAN, S. The Googlization of everything (and why we should worry). Berkeley and Los Angeles: University of California Press, 2011.

VERTESI, J. My experiment opting out of Big Data made me look like a criminal. Time, May 1, 2014.

WIENER, N. Cybernetics, or Control and communication in the animal and the machine. Cambridge (MA): MIT Press, 1961. 1989.

The human use of human beings: cybernetics and society. London: Free Association Books,

ZUBOFF, S. The age of surveillance capitalism: the fight for a human future at the new frontier of power. New York: PublicAffairs, 2019. 